\title{
Peer-Assisted Learning in General Internal Medicine: Pharmacy Students' Perspectives
}

\author{
Karen Kan, Janet Chow, Karen Ng, Rowena Malik, and Naomi Steenhof
}

\section{INTRODUCTION}

$\mathrm{D}$ emand for experiential pharmacy rotations in Canada has been increasing since the Association of Faculties of Pharmacy of Canada mandated that all pharmacy schools should have an entry-level Doctor of Pharmacy (PharmD) curriculum in place by $2020 .^{1}$ This change to the PharmD curriculum has meant an increase in mandatory experiential rotation time from 16 to 40 weeks. ${ }^{2}$ The response of some hospitals has been to innovate and explore new experiential education strategies, including novel methods of preceptorship, to increase capacity for learner rotations. ${ }^{3}$ One such model is peer-assisted learning (PAL), which has been described as "people from similar social groupings who are not professional teachers helping each other to learn and learning themselves by teaching." 4

Although PAL models are common in medicine and nursing education programs, they have not been widely adopted by pharmacy educators. Leong and others ${ }^{5}$ described a pharmacy PAL teaching model in an outpatient hemodialysis setting. The study was exploratory and followed a team of 4 pharmacy learners over a period of 3 weeks. The learners involved in the teaching model were a PharmD student, a pharmacy resident, a third-year co-op pharmacy student, and a fourth-year pharmacy SPEP (Structured Practical Experience Program) student. The clinical rotation involved direct patient care experiences in an outpatient clinic setting for all of the students, as well as teachingrelated experience for the senior students. As highlighted by Leong and others, ${ }^{5}$ the study limitations included the short duration of the intervention, the small number of students observed, and the practice setting, which was highly specialized. These authors concluded that although the PAL model offered a unique approach, it was unknown "[w] hether this approach would be practical in other settings, such as general medicine". ${ }^{5}$ Delgado and others ${ }^{6}$ described the expansion of student rotations in a Florida hospital, where PAL was used to facilitate the goal of obtaining pharmacy-generated medication histories and discharge counselling for all admitted patients. Pharmacists supervised a team of pharmacy residents and students in a format similar to the medical training model. In this setting, the PAL model demonstrated the value of additional students and was associated with an increase in the overall number of patient interventions. PAL also allowed for expansion of the discharge prescription program, whereby inpatient staff members worked in coordination with the outpatient pharmacy to offer bedside delivery of discharge medication prescriptions before patients left the hospital. ${ }^{6}$ In Alberta, a clinical teaching unit involving PAL was trialled on a general internal medicine unit for 5 student pharmacists, using preceptor-student ratios of $1: 2$ to $1: 5$. $^{7}$ Students reported that they were "very satisfied" with the overall program experience. This teaching unit showed increased placement capacity without negatively affecting students' learning experience. ${ }^{7}$

Although more pharmacist educators are now utilizing novel experiential education strategies, there is a paucity of data about the student experience in PAL. This paper describes implementation of a PAL model in a general internal medicine program, specifically highlighting the experiences of students over a 2-year period.

\section{DESCRIPTION OF THE PRACTICE SETTING}

Entry-level PharmD students from the Leslie Dan Faculty of Pharmacy, University of Toronto, Toronto, Ontario, who were completing Advanced Pharmacy Practice Experience (APPE) rotations between January 2014 and April 2016 in the general internal medicine program of Toronto Western Hospital participated in this PAL model. In this learning model, each student completed 2 consecutive 5 -week blocks on a general internal medicine unit, for a total rotation time of 10 weeks, 
This single copy is for your personal, non-commercial use only.

For permission to reprint multiple copies or to order presentation-ready copies for distribution, contact CHHP at publications@cshp.ca

\section{Table 1. Student Schedule for Advanced Pharmacy Practice Experience, Showing Staggered Rotation Start Dates}

Block No. and Timing

\begin{tabular}{|c|c|c|c|c|}
\hline Student & $\begin{array}{c}\text { Block 1 } \\
\text { Weeks 1-5 }\end{array}$ & $\begin{array}{c}\text { Block } 2 \\
\text { Weeks 6-10 }\end{array}$ & $\begin{array}{c}\text { Block } 3 \\
\text { Weeks 11-15 }\end{array}$ & $\begin{array}{c}\text { Block } 4 \\
\text { Weeks 16-20 }\end{array}$ \\
\hline Student A & Starts rotation & Completes rotation & & \\
\hline Student B & & Starts rotation & Completes rotation & \\
\hline Student C & & & Starts rotation & Completes rotatic \\
\hline
\end{tabular}

with staggered start times as detailed in Table 1. For each 5-week block, 1 pharmacist served as the preceptor for 2 APPE students concurrently. In each block, the more experienced student assisted with orientation of the incoming (less experienced) student to the patient chart and inpatient units (e.g., during block 2, student A oriented student B; see Table 1).

The general internal medicine program was located on 4 different inpatient units throughout the hospital. The program was delivered by 4 general internal medicine teams, 1 hospitalist team, and 1 family medicine inpatient team. Six full-time pharmacists (including all authors of this paper) provided care to the patients, with each of the 6 teams having its own designated pharmacist. The pharmacists spent $80 \%$ of their time on clinical duties and $20 \%$ of their time on dispensing and administrative responsibilities. The pharmacists had between 3 and 24 years of experience. Each of these pharmacists served as preceptor for students assigned to their respective teams.

Each pharmacist preceptor was responsible for overseeing the work flow of rotations within the team, facilitating group review of patient cases, and leading discussions of therapeutic topics as part of the requirements for the direct patient care APPE rotation. The 2 students on a given rotation would see patients admitted to the same team as the pharmacist preceptor. Students met with their preceptors to review cases either on one of the general internal medicine units or in a common area within the pharmacy department.

There was a need for adequate pharmacist staffing to minimize the need for cross-coverage and to maximize the amount of time spent with learners. The general internal medicine pharmacists decided that pharmacists who were performing preceptor duties would not be asked to provide cross-coverage for another team's pharmacist. Consequently, the cross-coverage time for the remaining pharmacists was increased slightly.

The preceptors participated in training modules through the Leslie Dan Faculty of Pharmacy before taking on preceptorship duties with the APPE students. An orientation manual was developed by the general internal medicine pharmacists and was given to each student on the first day with the team. The orientation manual included a general schedule for daily workflow (e.g., time of inpatient care rounds, time to complete patient care plans, time for patient case review with the preceptor) and a checklist for physical orientation (e.g., location of inpatient units, computer workstations, patient charts). Although the orientation manual did not change throughout the 2 years of the study, the preceptors became more structured in setting student expectations. To facilitate coordination of the PAL rotation, which required that each student be present for 2 consecutive 5-week blocks (in contrast to the traditional scheduling of APPE students for a single 5-week block), advance planning between the site and the faculty was required.

\section{EVALUATION OF THE PROGRAM}

Surveys were distributed to the pharmacy students at the end of each block. The survey consisted of Likert-scale and open-ended questions to assess the impact of the PAL model on the quality of the rotation and the learning experience. Students' responses to the survey were evaluated qualitatively to identify any emerging strengths and weaknesses that might help to improve the learning model. This survey was conducted under the authorization of the University Health Network Research Ethics Board, which waived the need for informed consent.

Between January 2014 and April 2016, 10 students completed a total of 12 PAL rotations in the general internal medicine program (with 2 of the students each having 2 rotations in the program). Nine of these 10 students submitted a total of 11 feedback forms, so feedback was available for $92 \%$ of the rotations. Within that timeframe, 5 pharmacists served as preceptors for the rotations.

The students were given an opportunity to comment on the strengths of the rotation and to describe areas of improvement for the PAL model (Box 1). The students indicated that they had had a positive learning experience working with their respective peers, and that the learning model had increased their exposure to a greater variety of patient cases than might otherwise have occurred. They perceived that their skills relating to documentation and care plan development were improved, and they saw benefit to working with a peer who had already completed a rotation at the site, because he or she could provide orientation to the patient chart and inpatient units. However, some students felt that having another peer on the rotation divided the preceptor's attention, which meant that not enough time was available to discuss all patient issues with the preceptor. Some respondents also indicated that they would have liked to 
Box 1. Selected Student Comments in Response to Open-Ended Feedback Questions

\section{Strengths}

- "By sitting in on peer discussion it allowed me to be a part of learning a new topic that wasn't assigned to me"

- "Fostered collaboration between my peer and [me]"

- "Allowed me to adapt my learning style, documentation practices and work-up process above and beyond what I could have accomplished on my own"

- "I could relate with someone from my class with similar experience and skill set/background knowledge"

- "My peer did an excellent job teaching me how to read paper charts, navigate electronic patient record and document"

- "Most importantly, my peer taught me how to present patient cases to preceptors"

Areas of improvement

- "Scheduled time each day set aside for peer discussion of patient cases would be beneficial rather than informal meetings throughout the day"

- "Sometimes led to the preceptor not having enough time for each student to update all the patients"

- "Differences in the skill level of each student would also help in teaching [in the PAL model]"

- "Give student opportunities to shadow other [more experienced] students or residents"

$\mathrm{PAL}=$ peer-assisted learning.

have more peer evaluation and feedback built into the rotation, to foster a more collaborative learning environment.

Students were asked to rate their views regarding peer and preceptor interactions as related to activity-specific tasks completed within the rotation using a 5-point Likert scale. Overall, the majority agreed that they felt comfortable having their peer present during therapeutic topic discussions (Figure 1). Similarly, 60\% (6/10) of the students strongly agreed and $40 \%$ (4/10) agreed that they felt comfortable having a peer present during daily patient reviews.

However, when students were asked about having topic and case discussions in a 1:1 setting with the preceptor, the results were more divergent. Only 1 respondent $(9 \%, 1 / 11)$ expressed a preference for 1:1 topic discussions with the preceptor, and only 2 respondents $(18 \%, 2 / 11)$ agreed that they would prefer to have 1:1 case discussions with the preceptor (Figure 2).

A majority of the students agreed that their ability to provide constructive feedback, their time management skills, and their confidence had improved since completing the PAL rotation (Figure 3). In total, 73\% (8/11) of respondents agreed or strongly agreed that their learning was enhanced.

Overall, $82 \%(9 / 11)$ of the students agreed or strongly agreed that if given the chance, they would elect to participate in a PAL model again; one student was neutral on this question and one student strongly disagreed. The student who was neutral in the first APPE block subsequently agreed to enroll in the model again after the second rotation. The student who strongly disagreed commented that the preceptor's time was divided in half, and the student felt that there was no benefit from being paired with a peer at the same level of education.

\section{IMPLICATIONS AND SIGNIFICANCE FOR PRACTICE}

This study evaluated and reported on the quality of a PAL model within a general internal medicine program from the pharmacy students' perspective. The 2:1 learner-to-preceptor ratio provided an opportunity to accommodate a greater number of pharmacy students without sacrificing the quality of learning. Students consistently commented that they preferred reviewing patient cases and having discussions of therapeutic topics with another peer present rather than 1:1 with the preceptor. They felt comfortable presenting cases in front of their peers and felt a greater sense of collaboration rather than competition. Most students appreciated exposure to a greater number of patient cases through the peer presentations, and they learned from the other student's presentation skills.

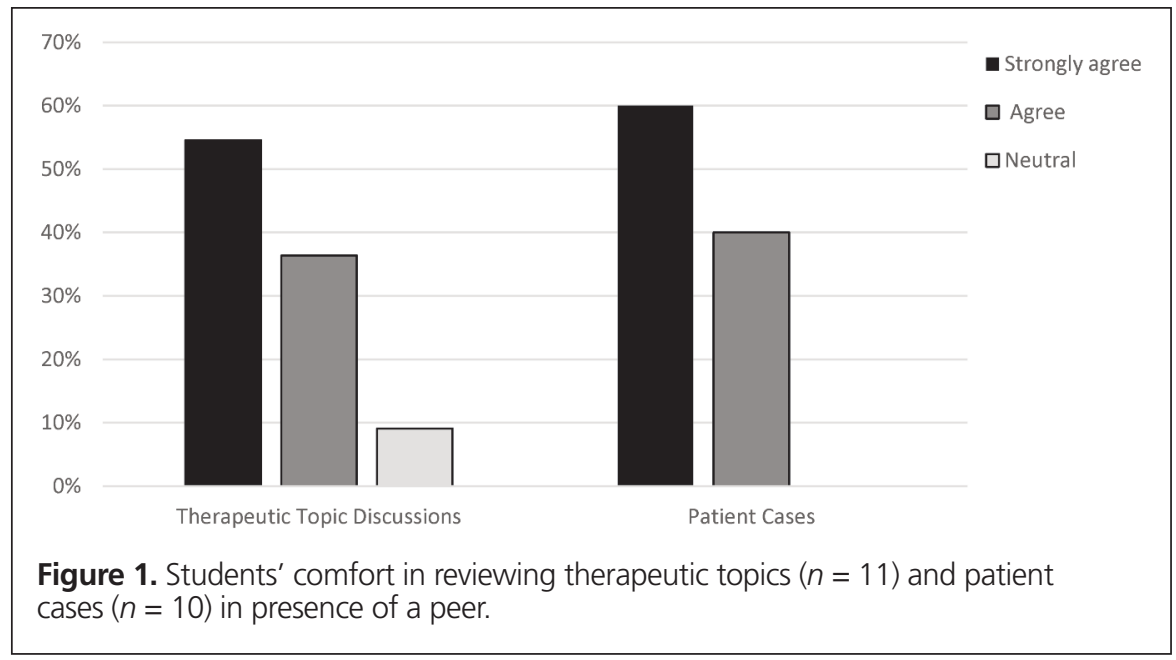



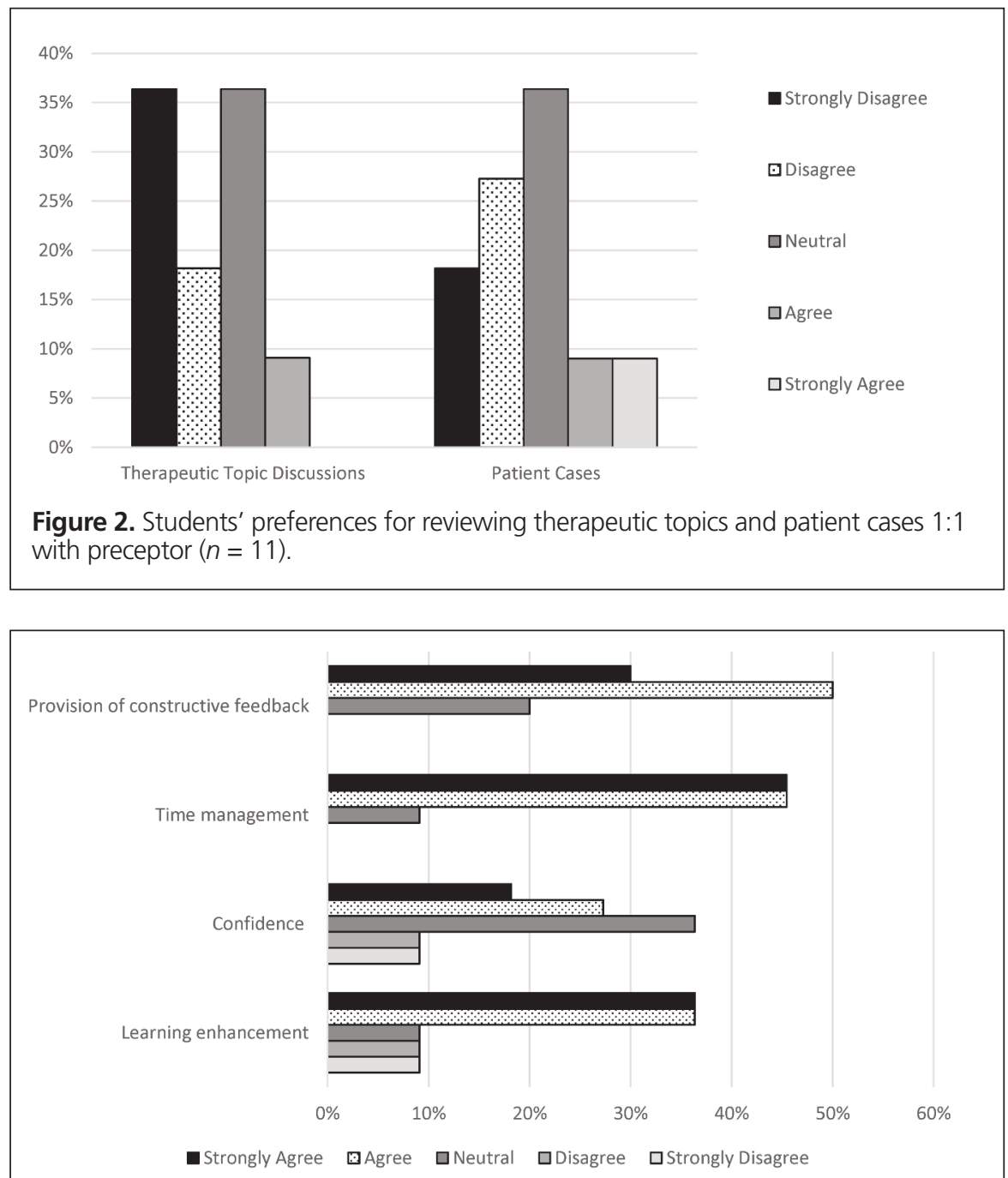

Figure 3. Students' perceptions of increase in various skills ( $n=10$ or 11).

Despite the strengths described, this study had some limitations. The survey was not validated, and some students found the wording unclear. In particular, the statement "the presence of another student within the peer to peer model affected my preceptor's evaluation of me" was found to be confusing and unnecessary. Many students did not feel that their preceptor's evaluation would be affected by the presence of a peer learner. In terms of the PAL model, the role of the "experienced" student in orienting and teaching the new student relied heavily on the first student's leadership skills and initiative. The need for leadership and initiative was not an issue in most rotations, but the expectations for the "experienced" peer learner could have been presented more explicitly (e.g., in an information package) to facilitate consistent orientation. It was also noted that students' feedback on their peers was variable. Such variation can be expected with any new teaching method and would likely diminish with greater experience and standardization of the preceptorship processes within the PAL model.
Given the increasing need for preceptor availability, novel teaching methods are required to give students greater exposure to clinical areas such as general internal medicine. ${ }^{3}$ To contrast with the feedback gained from the students' perspective in the study reported here, it would be interesting to evaluate the same model from the preceptors' perspective in the future. Furthermore, this PAL model could be expanded to allow for tiered teaching in the future, whereby an APPE student would be paired with an Early Practice Experience student or a pharmacy resident would be paired with an APPE student.

\section{CONCLUSION}

Given students' feedback on this PAL model, a staggered rotation schedule and a 2:1 ratio of learners to preceptors appears promising for enhancing learners' experience in a general internal medicine program. 


\section{References}

1. Position statement and joint resolution on the Doctor of Pharmacy (PharmD) for the first professional degree at universities in Canada. Association of Faculties of Pharmacy of Canada and Association of Deans of Pharmacy of Canada; 2010 Feb [cited 2018 Mar 19]. Available from: www.afpc.info/sites/default/ files/AFPC_ADPC_PharmD_Position_Statement_Resolution_Sept_2010.pdf

2. Accreditation standards for the first professional degree in pharmacy programs. Toronto (ON): Canadian Council for Accreditation of Pharmacy Programs; 2013 Jan [revised 2014 Jul; cited 2016 Oct 20]. Available from: http:// ccapp-accredit.ca/wp-content/uploads/2016/01/CCAPP_accred_standards_ degree_2014.pdf

3. Cameron K, Fernandes O, Musing ELS, Raymond C. Increasing capacity for experiential rotations for pharmacy learners: lessons learned from a multisite teaching hospital. Can J Hosp Pharm. 2016;69(1):23-9.

4. Topping KJ. The effectiveness of peer tutoring in further and higher education: a typology and review of the literature. Higher Educ. 1996;32(3):321-45.

5. Leong C, Battistella M, Austin Z. Implementation of a near-peer teaching model in pharmacy education: experiences and challenges. Can J Hosp Pharm. 2012;65(5):394-8

6. Delgado O, Kernan WP, Knoer SJ. Advancing the pharmacy practice model in a community teaching hospital by expanding student rotations. Am J Health Syst Pharm. 2014;71(21):1871-6.

7. Lindblad AJ, Howorko JM, Cashin RP, Ehlers CJ, Cox CE. Development and evaluation of a student pharmacist clinical teaching unit utilizing peer-assisted learning. Can J Hosp Pharm. 2011;64(6):446-50.
Karen Kan, HonBSc, BScPhm, ACPR, is with the Department of Pharmacy, University Health Network, Toronto, Ontario.

Janet Chow, BScPhm, ACPR, PharmD, is with the Department of Pharmacy, University Health Network, Toronto, Ontario.

Karen Ng, BScPhm, ACPR, PharmD, is with the Department of Pharmacy, University Health Network, Toronto, Ontario.

Rowena Malik, BScPhm, is with the Department of Pharmacy, University Health Network, Toronto, Ontario.

Naomi Steenhof, BSc(Hons), BScPhm, ACPR, is with the Department of Pharmacy, University Health Network, and the Leslie Dan Faculty of Pharmacy, University of Toronto, Toronto, Ontario.

Competing interests: None declared.

\section{Address correspondence to:}

Naomi Steenhof

Department of Pharmacy

University Health Network

200 Elizabeth Street, 1ES-565

Toronto ON M5G 2C4

e-mail: naomi.steenhof@uhn.ca

Funding: None received. 